\title{
Pharmacokinetics of Tetracycline and Tetracycline Loaded Nanoemulsion Formula in Rabbits
}

\author{
Aziza M.M. Amer ${ }^{1 *}$, Shymaa A. El Badawy ${ }^{1}$, Mohamed S. Saber ${ }^{2}$, Omar A. Ahmed- Farid ${ }^{3}$, \\ Wessam H. Abd-Elsalam ${ }^{4}$, Mohamed M. Amer ${ }^{5}$
}

${ }^{1}$ Deptartment of Pharmacology, Faculty Veterinary Medicine, Cairo University, Giza, Egypt; ${ }^{2}$ PhD Student in Pharmacology, Veterinary Service division, Ministry of Deviance, Egypt; ${ }^{3}$ Deptartment of Physiology NODCAR, Giza, Egypt; ${ }^{4}$ Department of Pharmaceutics and Industrial pharmacy, Faculty of Pharmacy, Cairo University, Cairo, Egypt; ${ }^{5}$ Department. of Poultry Diseases, Faculty Veterinary Medicine, Cairo University, Giza, Egypt.

\begin{abstract}
Nano-sized drug delivery systems used to improve drug pharmacokinetics especially bioavailability. Different tetracycline loaded nanoemulsions were formulated and evaluated for thermodynamic stability, morphology, droplet size and zeta potential measurements. Pharmacokinetic of TC-NE (10\% Mig, 50\% S/CoS and 40\% water with drug concentration of $5 \%, \mathrm{w} / \mathrm{w}$ ) was investigated in rabbits following a single oral and IV doses ( $50 \mathrm{mg} / \mathrm{kg}$ bwt) and compared to tetracycline $\mathrm{HCl}$ powder (TC- Powder) at the same dose. Tetracycline concentrations were determined in plasma samples using standard high performance liquid chromatography (HPLC) procedure. Following IV injection higher AUC0-inf $(83.3 \pm 4.2$ and $74.8 \pm 2.9 \mu \mathrm{g} / \mathrm{ml} . \mathrm{h})$ and volume of distribution (Vdss) $(0.78 \pm 0.06 \mathrm{~L} / \mathrm{kg}$ and $0.71 \pm 0.10 \mathrm{~L} /$ $\mathrm{kg}$ ) reported for TC-NE compared to TC-Powder, respectively. Furthermore, after oral administration, TC-NE was slowly absorbed and eliminated than TC-Powder with longer $\mathrm{t}_{1 / 2 \mathrm{ka}}(0.518 \pm 0.091 \mathrm{~h}$ and $0.253 \pm 0.024 \mathrm{~h})$ and $\mathrm{t}_{1 / 2 \beta}(4.22$ $\pm 1.67 \mathrm{~h}$ and $3.33 \pm 0.68 \mathrm{~h}$ ), respectively. Moreover, the time at which maximum tetracycline plasma concentration achieved $\left(\mathrm{T}_{\max }\right)$ was $0.869 \pm 0.059 \mathrm{~h}$ for TC--NE and $0.397 \pm 0.033 \mathrm{~h}$ for TC-Powder. Significantly higher area under curve AUC $_{0-\mathrm{t}} 20.4 \pm 1.5 \mu \mathrm{g} / \mathrm{ml} . \mathrm{h}$ and $11.1 \pm 0.6 \mu \mathrm{g} / \mathrm{ml}$.h and consequently higher bioavailability $29.2 \pm 2.3 \%$ and $13.9 \pm$ $0.8 \%$ was recorded for TC-NE than TC-Powder, respectively. Following oral admistiration TC-NE formula exhibited prolonged $\mathrm{T}>\mathrm{MIC}$ of $10.36 \pm 0.64 \mathrm{~h}$ compared to $7.1 \pm 0.32 \mathrm{~h}$ in TC-powder. In conclusion, the prepared Tetracycline loaded nanoemulsion formulation has improved oral bioavailability and prolonged the blood concentration time than TC-Powder. Further clinical studies are required to justify dosage that supports clinical efficiency.
\end{abstract}

Keywords | Pharmacokinetics, Tetracycline, Tetracycline-loaded nanoemulsions, HPLC, Rabbits

Received | Novemebr 04, 2019; Accepted | December 26, 2019; Published | January 20, 2020

*Correspondence|AzizaM.M.Amer,Deptartment ofPharmacology,Faculty VeterinaryMedicine,CairoUniversity,Giza,Egypt;Email:aziza.mahrous@gmail.com Citation | Amer AMM, El Badawy SA, Saber MS, Farid OAA, Abd-Elsalam WH, Amer MM (2020). Pharmacokinetics of tetracycline and tetracycline loaded nanoemulsion formula in rabbits. Adv. Anim. Vet. Sci. 8(2): 130-139.

DOI | http://dx.doi.org/10.17582/journal.aavs/2020/8.2.130.139

ISSN (Online) | 2307-8316; ISSN (Print) | 2309-3331

Copyright $($ C 2020 Amer et al. This is an open access article distributed under the Creative Commons Attribution License, which permits unrestricted use, distribution, and reproduction in any medium, provided the original work is properly cited.

\section{INTRODUCTION}

$\mathrm{T}$ etracycline (TC) is a polymeride antibiotic produced by the Streptomyces genus of Actinobacteria. Tetracycline hydrochloride formula is $\mathrm{C}_{22} \mathrm{H}_{24} \mathrm{~N}_{2} \mathrm{O}_{8}$ with CAS Number 64-75-5 (European Pharmacopoeia (EP) Reference Standard with relative molecular weight of 515.3). Tetracycline has low stability in strong acid or basic media (Oka, 1995). TC is an amphoteric molecule with three pKa values (3.3, 7.7 and 9.7). Thus, TC exists as a cationic, zwitterionic and anionic species under acidic, curcimneutral and alkaline conditions, respectively. Under acidic conditions, a reversible epimerization occurs at position of $\mathrm{C}_{4}$, forming 4-epi-TC, results in the relatively high solubility of TC (McCormick, 1957). Tetracycline is a time-dependent antimicrobial (Mestorino and Errecalde, 2012) that exerts a bacteriostatic action against various bacteria including mycoplasma, rickettsia, and chlamydia, in addition to some protozoa, Rickettsiae, and Ehrlichiae (Riviere and Spoo, 2001; Papich, 2016). 
Different members of tetracycline were investigated in rabbits. Chlortetracycline was administered orally in a dose of $50 \mathrm{mg} / \mathrm{kg} \mathrm{b}$. wt. every 24 hours (Carpenter and Christopher, 2018). While Doxycycline (Long-acting tetracycline) was given orally $(2.5 \mathrm{mg} / \mathrm{kg}$ twice daily), that was efficient against anaerobes and intracellular bacteria and safe in rabbits with renal problems as it is excreted via the intestine (Carpenter and Christopher, 2018). In addition, Oxytetracycline was administered in rabbits in the doses of $50 \mathrm{mg} / \mathrm{kg}$ twice daily per Os and $15 \mathrm{mg} / \mathrm{kg} /$ day SC or IM (Saunders and Davies, 2005). Moreover, Tetracycline was used in rabbits orally $(50 \mathrm{mg} / \mathrm{kg}$ every 8-12 hours in drinking water) for treatment of Tyzzers disease, Pasteurellosis and Mycoplasmosis (Carpenter and Christopher, 2018).

Pharmacokinetics of tetracycline hydrochloride was studied in various animals including pigs (Kniffen et al., 1989), man (Agwuh and MacGowan, 2006), rabbits (Percy and Black, 1988) and chickens (Anadon et al., 1985). Following repeated oral administration of tetracycline (35 $\mathrm{mg} / \mathrm{kg}$ b.wt. for 5 days) in rabbit, There were no TC residues detected in the muscular and hepatic tissues at (7 and 14) days post last dose, respectively (Abdel Aziz et al., 2017). The antibacterial activities of tetracycline hydrochloride (TC-powder) and tetracycline nanoemulsion (TC-NE) formulations were previously evaluated on standard and field bacterial strains (Saber et al., 2019a). Moreover, Saber et al. studied the biochemical and pathological effects of the former formulations following repeated oral administration for 7 days. Four days after the last dose, there were no detectable residues in the liver, kidney and muscle tissues (Saber et al., 2019b).

The commonly used route for $\mathrm{TC}$ is the oral route with low oral bioavailability (Ahmad et al., 2011). Absorption of hydrophobic drugs might be improved by their incorporation into inert lipid vehicles and surfactants (Ahmad et al., 2012; Gupta et al., 2013; Costanzo and Angelico, 2019). Nanoemulsions are biocompatible, biodegradable, physically stable and relatively easy to produce on a large scale. Therefore, Nanoemulsions might be considered as ideal delivery system for therapeutic agents (Li et al., 2008; Aboofazeli, 2010). Intravenous (IV) administration of nanoemulsions had proved advantageous particularly due to their droplet size $(<1 \mu \mathrm{m})$ (Tamilvanan et al., 2005) that provides a large interfacing area for better drug absorption (Chime et al., 2014).

The incorporation of TC, a water soluble drug, in the nanoemulsion system is suspected to change its release behaviour and hence modify its pharmacokinetic parameters. Therefore, the aim of this study was to prepare and characterize a nanoemulsion formula of tetracycline hydrochloride (TC-NE). As well as to compare pharmacokinetics of tetracycline hydrochloride powder (TC-Powder) with formulated TC-NE following oral and IVadministrationinhealthywhitemale NewZealand rabbits.

\section{MATERIAL AND METHODS}

\section{Chemicals}

Miglyol ${ }^{\circledR} 812$ (Mig) (Gattefossé, St-Priest, France). Isopropyl myristate (IPM) (Sigma Aldrich Chemical Co., St. Louis, MO, USA). Cremophor RH40 (BASF, Ludwigshafen, Germany). Polyethylene glycol 400 (PEG 400), sodium benzoate (Sigma-Aldrich, Inc., cairo Egypt). Tetracycline hydrochloride pure powder 100\% (El-Nasr pharmaceutical chemicals Co., Abu-Zaabal, Egypt). calcium gluconate (Cal-Nate, Armitage-Carroll, London, Ontario). All chemicals were of analytical grade and used as received.

\section{Preparationand characterization OfTETRACYCline} HYDROCHLORIDE NANOEMULSION (TC-NE)

\section{CONSTRUCTION OF PHASE Diagrams}

The phase diagrams constructed using Tri-plot software (Ver. 4.1.2, D. Graham and N. Midgley, Loughborough University, Leicestershire, England) as described by ElAssal et al. (2018). Nanoemulsion systems consisting of oils (IPM or Mig), surfactant (Cremophor RH40) and a cosurfactant (PEG 400) formulated by the water titration method as described previously (Ammar et al., 2009). Briefly, transparent and homogeneous blends of oils and Surfactant/Cosurfactant (S/CoS) mixtures (1:1, 1:2 and $2: 1$, respectively) ranging from $9: 1$ to $1: 9(\mathrm{w} / \mathrm{w})$ ready by constant stirring. After each addition of water, systems were settled for equilibration and observed for phase transparency and flowability.

\section{Preparation of Tetracycline HCl-loaded NANOEMULSIONS (TC-NE)}

Certain systems; namely, F1, F2 and F3 selected and formulated by mixing specified weight ratios of oil $(10,15$ and $20 \%, \mathrm{w} / \mathrm{w})$, a fixed $\mathrm{S} / \mathrm{CoS}$ concentration $(50 \%, \mathrm{w} / \mathrm{w})$ and water $(40,35$ and $30 \%, w / w)$, respectively. TC-NE $(5 \%, \mathrm{w} / \mathrm{w})$ formulated and preserved with sodium benzoate $(0.01 \%, w / w)$. In order to rule out any possible effects of the components of nanoemulsions on biological tissues, a nanoemulsion lacking the drug was prepared and tested along with drug loaded preparation. The formulae kept at room temperature $\left(25^{\circ} \mathrm{C}\right)$ till further use. Composition of the investigated formulae presented in (Table 1).

\section{Characterization of Tetracycline-LOAded}

\section{FORMULAE}

Thermodynamic STABILITY STUdiES

The thermodynamic stability of TC-NE assessed according to the protocol designed by Shafiq et al. (2007). 
Firstly, nanoemulsions exposed to six heat $\left(45^{\circ} \mathrm{C}\right)$ - cool $\left(4{ }^{\circ} \mathrm{C}\right)$ cycles. This was achieved through storage at each temperature for $48 \mathrm{~h}$. Secondly; nanoemulsions subjected to centrifugation at $3500 \mathrm{rpm}$ for $30 \mathrm{~min}$. Finally nanoemulsions went through three freezes $\left(-21^{\circ} \mathrm{C}\right)$ - thaw $\left(25^{\circ} \mathrm{C}\right)$ cycles and this was accomplished by storage at each temperature for $48 \mathrm{~h}$.

\section{NANOEMULSION DROPLET SIZE ANALYSIS}

The mean droplet size (MDS) of nanoemulsions and the polydispersity index (PDI) determined by Photon Correlation Spectroscopy (PCS) using a Zetasizer Nano ZS (Ver.6.20, Malvern Instruments Ltd., Worcestershire, England). The technique explores the oscillations in light scattering caused by the Brownian motion of particles and thus assumes the average droplet size. The zeta potential $(\mathrm{ZP})$ values of nanoemulsions recorded by the electrophoretic light scattering (ELS) technology using a Laser Doppler Anemometer coupled with the same equipment. The method elucidates the electrophoretic mobility of globules under an electric field. All measurements were carried out, in triplicate, at room temperature $\left(25^{\circ} \mathrm{C}\right)$.

\section{Transmission ELECTRON Microscopy (TEM)}

The morphological features of the selected TC-NE visualized via TEM. One drop of the formula loaded onto a copper grid, and the excess was absorbed with filter paper. The grid air-dried for $10 \mathrm{~min}$. Examination of the grid was achieved via a transmission electron microscope (Jeol JEM 1230, Tokyo, Japan).

\section{Pharmacokinetic STUdy}

\section{Animals}

The protocol was approved by Institutional Animal Care and Use Committee of Cairo University (IACUC). Sixteen white male New Zealand rabbits weighing (3.43.6) $\mathrm{kg}$ were obtained from local farms, housed indoor at laboratory animal facilities of faculty of veterinary medicine, Cairo University and fed commercial pellets and fresh hay ad libitum with free access to drinking water.

\section{DRUG PREPARATION AND ROUTE OF ADMINISTRATION}

ForIV administration, crystalline tetracycline hydrochloride (TC-Powder) was dissolved in a $23 \%$ solution of sterile calcium gluconate at concentration of $50 \mathrm{mg}$ of tetracycline $\mathrm{HCl}$ per $\mathrm{mL}$ of solution. At a dose of $1 \mathrm{ml} / \mathrm{kg}$.b.wt, the prepared solution was administered intravenously via IV catheter in the ear vein or orally through a mouth gag using $3 \mathrm{~mL}$ syringe according to group allocation. Tetracycline $\mathrm{HCl}$ nanoemulsion (TC-NE) prepared in a concentration of $50 \mathrm{mg} / \mathrm{ml}$ and used for oral or IV administration $(1 \mathrm{ml} /$ $\mathrm{kg} \mathrm{b} \mathrm{wt)} \mathrm{as} \mathrm{described} \mathrm{above.} \mathrm{For} \mathrm{sequential} \mathrm{blood} \mathrm{sampling,}$ ear vein catheters were applied as described by (Echols and Pollock, 2013).

\section{EXPERIMENTAL DESIGN}

Pharmacokinetics of tetracycline $\mathrm{HCl}$ was investigated in rabbits following oral and IV administration of tetracycline $\mathrm{HCl}$ Loaded nanoemulsion (TC-NE) and tetracycline $\mathrm{HCl}$ powder (TC-Powder). Formulations were used at the same dose, for both routes to investigate the bioavailability and sustainability of the new formula. Following one week of accommodation, rabbits were randomly allocated into two groups of eight animals each. Animals of first group received TC-NE in single IV dose $50 \mathrm{mg} / \mathrm{kg}$ b wt. via intravenous catheter. Fourteen days were allowed to make sure complete clearance of TC from their bodies, then the animals of the 1 st group received TC-NE at the same dose $(50 \mathrm{mg} / \mathrm{kg} \mathrm{b} \mathrm{wt}$ ) orally through a mouth gag. The second group received single dose of TC-Powder $50 \mathrm{mg} / \mathrm{kg}$ b.wt, via intravenous catheter. Fourteen days later the second group received single oral dose of TC-Powder $(50 \mathrm{mg} / \mathrm{kg}$ b wt.).

Blood samples were collected through ear vein catheter at the following time intervals; $0.083,0.25,0.5,1,2,4,6,8$, 10, 12 and 24 hours after administration. Blood samples were collected into clean sterile heparinized centrifuge tubes, then centrifuged at $3000 \times \mathrm{g}$ for $15 \mathrm{~min}$. A $2 \mathrm{ml}$ of the plasma were harvested from each sample (Parasuraman, et al., 2010; Baby et al., 2017) and stored at $-70{ }^{\circledR} \mathrm{C}$ until analyzed within 1 month for determination of Tetracycline $\mathrm{HCl}$ concentration using HPLC.

\section{HPLC DETERMINATION OF TETRACYCLINE IN PLASMA} SAMPLES

\section{SAMPLE PREPARATION}

The plasma samples were prepared guided by Chang et al. (1992) and Shalaby et al. (2011). The extraction was conducted using citrate buffer $(\mathrm{pH} 4)$ plus trichloroacetic acid (80:20\%), followed by centrifugation $1000 \mathrm{~g}$ for 10 minutes then elution using $0.01 \mathrm{M}$ methanolic oxalic acid.

\section{Chromatographic CONDITIONS}

Agilent HPLC 1260 series (5301 Stevens Creek Blvd Santa Clara, CA 95051 United States). Separation done using Agilent ZORBAX StableBond SB-C18 80Å $3.5 \mu \mathrm{m}, 4.6 \times 75 \mathrm{~mm}$ column. Injection was accomplished using a $20 \mu \mathrm{L}$ loop injector and blunt-needle glass syringe (Hamilton Co., USA). Mobile phase consisted of A: 0.025 $\mathrm{MKH} 2 \mathrm{PO} 4$ in $\mathrm{H} 2 \mathrm{O}$ with $\mathrm{pH} 3$ and $\mathrm{B}$ : CAN, gradient at $5 \% \mathrm{~B}$ to $60 \% \mathrm{~B}$ in $10 \mathrm{~min}$ then $60 \% \mathrm{~B}$ to $5 \% \mathrm{~B}$ in $2 \mathrm{~min}$, wavelength was $350 \mathrm{~nm}$, flow rate was $1 \mathrm{ml} / \mathrm{min}$ that performed at Temperate of $25^{\circ} \mathrm{C}$.

\section{STANDARD SOLUTIONS AND CALIBERATION CURVES}

The HPLC method was validated using ICH guidelines. Standards run before and after the samples and blank samples were included with each set. Six calibration curves constructed on six separate days to check the linearity of each calibration curve. 
Standards and quality control QC stock solutions of tetracycline were prepared in phosphate buffer solution $\mathrm{pH} 3: \mathrm{ACN}$ (50:50\%) to produce working stock solutions of $500,100,10,1,0.01 \mu \mathrm{g} / \mathrm{mL}$. Then, stock solutions were stored at about $5^{\circ} \mathrm{C}$ and used to prepare plasma calibration standards. Samples for recovery, precision and accuracy were prepared by spiking control rabbits plasma in bulk at proper concentrations $(0.01,1,10$ and $15 \mu \mathrm{g} / \mathrm{mL})$ and 100 $\mu \mathrm{L}$ volumes were aliquot into different tubes and stored as samples at $-80^{\circ} \mathrm{C}$ until analysis. Calibration curves were obtained by plotting the peakarea ratio of tetracycline against the nominal concentration of calibration standards.

The Tetracycline concentrations used were 500, 100, 10, 1, $0.01 \mu \mathrm{g} / \mathrm{mL}$. The results fitted to linear regression analysis without the introduction of weighing factors. Limit of detection (LOD) and limit of quantification (LOQ) calculated as mentioned by El Badawy et al. (2015) and to be 10 and $30 \mathrm{ng} / \mathrm{ml}$, respectively.

\section{Precision ANd aCcuracy}

The intra-assay precision and accuracy estimated by analyzing three replicates containing tetracycline at three different QC levels i.e. 1, 10 and $15 \mu \mathrm{g} / \mathrm{mL}$. The interassay precision determined by analyzing the three levels QC samples on three different runs. The criteria for acceptability of the data included accuracy NMT 2\% RSD.

\section{EXTRACTION RECOVERY}

The recovery determined by comparing peak areas of spiked plasma extracts with those of un-extracted prepared in phosphate buffer: ACN (50:50\%). The recovery value calculated at the various concentrations of tetracycline.

\section{Pharmacokinetic Modeling}

Pharmacokinetic values calculated using PK solver program (Zhang et al., 2010) for each rabbit. Bioavailability (F) of tetracycline after oral injection calculated as a percentage using following standard equation: $\mathrm{F} \%=$ (AUC0-inf.oral $/$ AUC0-inf.iv) X 100 (Toutain and Bousquet-Melou, 2004). The minimal effective concentration considered based on the in-vitro MIC for Staphylococcus aureus 6538 was $0.14 \mu \mathrm{g} / \mathrm{mL}$ in our earlier work on the same formulations (Saber et al., 2019a). The time that plasma tetracycline concentration exceeded $0.14 \mu \mathrm{g} / \mathrm{mL}$ ( $\mathrm{T}$ > MIC) determined for each rabbit from the concentrationtime relationship curve.

\section{STATISTICAL ANALYSIS}

Data presented as mean \pm SD. Selected pharmacokinetic values compared following IV and oral administration of both tetracycline formulations (TC-NE and TC- Powder) using repeated measure ANOVA, using procedure and an autoregressive (1) covariance matrix (SAS 9.3, SAS Inc, Cary, NC). A $\mathrm{P}$ value $<0.05$ was considered significant $\left(^{*}\right)$ while, $\mathrm{P}$ value $<0.05$ was considered highly significant ${ }^{(* *)}$.

\section{RESULTS}

\section{Preparation of tetracycline nanoemulsion \\ PSEUdOTERNARY PHASE DIAGRAMS}

The phase diagrams of 2 oils (IPM- and Mig) based systems showed the clear zones at the investigated three Cremophor RH40/PEG 400 (1:1,1:2 and 2:1) mass ratios were graphically presented in (Figure 1). As noticed from the phase diagrams, there is a direct relation between the $\mathrm{S} / \mathrm{CoS}$ ratio and the clear area. The largest clear zones accomplished with systems prepared using S/CoS mixture ratios of 1:1. Therefore, three formulae were chosen from this phase diagram and their compositions are listed in (Table 1). To ensure the safety of the ready formulae, the least amount $(50 \%)$ of $\mathrm{S} / \mathrm{CoS}$ mixture. Three formulae (F1, F2, and F3) selected containing Mig at concentrations of 10,15 and $20 \%, 50 \%$ of S/CoS (1:1) and water at 40,35 and $30 \%$.
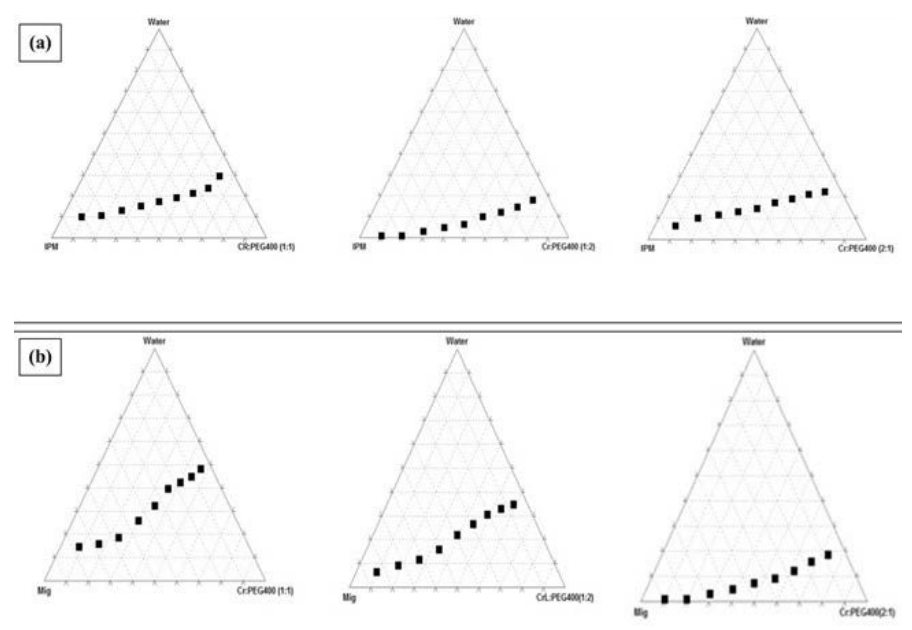

Figure 1: Pseudoternary phase diagrams of (a) IPM and (b) Mig based systems showing clear zones using Cremophor RH40/PEG 400 at indicated mass ratios.

\section{Characterization OF TETRACyCline-LOADED} NANOEMULSION (TC-NE)

\section{THERMODYNAMIC STABILITY STUDIES}

The selected systems were assessed through three stages; cycles, centrifugation, and finally cycle. The systems remained clear through the alternate cycles. Throughout the second stage; centrifugation, signs of creaming and phase separation was observed with F3. Upon freezing the systems at $-21^{\circ} \mathrm{C}$, turbidity was detected, but then the systems became clear again on thawing.

Mean droplet Size (MDS) AND ZETA Potential (ZP) MEASUREMENTS

The mean droplet sizes (MDS) of the selected formulae were shown in (Table 1). The MDS of the selected formulae ranged from $32.33 \pm 3.81$ to $101.5 \pm 9.86 \mathrm{~nm}$. The PDI of 
all TC-NE were in the range of $0.11 \pm 0.01: 0.41 \pm 0.07$ revealing narrow size distributions and good homogeneity (Table 1). The formulated TC-NE possessed $\mathrm{ZP}$ values ranged from $-25.45 \pm 3.43$ to $-33.47 \pm 2.11 \mathrm{mV}$ (Table 1 ).

\section{TRANSMISSION ELECTRON MICROSCOPY}

TEM micrography showed spherical globules with uniform droplet size distribution. Representative micrography of F1 and F2 was shown in Figure 2.
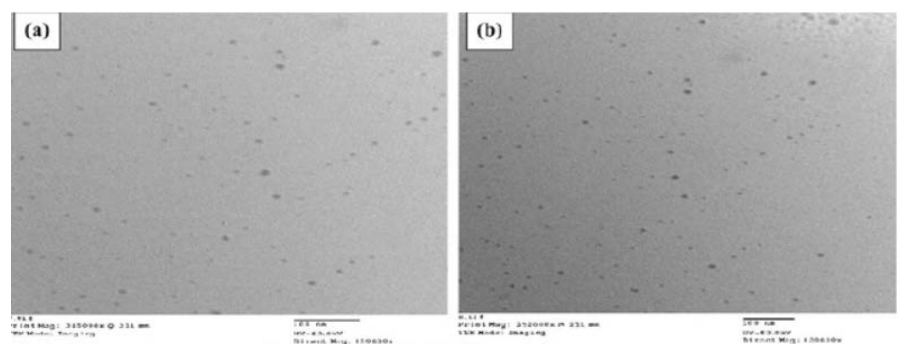

Figure2: Transmission electron micrographs of (a) F1 and (b) F2.

The globules of F1 (Figure 2a) and F2 (Figure 2b) seemed to have a comparable size to that calculated by photon correlation spectroscopy.

\section{Pharmacokinetic ANALYSIS}

In this study, there was no apparent clinical sign noticed in rabbits received a single dose $(50 \mathrm{mg} / \mathrm{kg})$ of TC-NE formula or TC-Powder in both IV and oral routes. Graphs of the tetracycline-time relationship in plasma after a single IV and oral administration of TC-NE and TCPowder were presented in (Figures 3 and 4). The highest plasma tetracycline concentration was after 0.5 and 1 hour from administration and persisted for at least 7 hours and 11 hours after oral administration in TC-Powder and TC-NE groups, respectively. The prolonged persistence of tetracycline in rabbits plasma after IV and oral administration of TC-NE enhanced the time dependent activity of tetracycline. The sustained release suggestion of the TC-NE formula is indicated by the prolonged absorption half-life time $t 1 / 2 \mathrm{ka}(0.518 \pm 0.091 \mathrm{~h}$.$) and$ distribution half-life time $t 1 / 2 \alpha(0.550 \pm 0.090$ h. $)$ than that in TC-powder $(\mathrm{t} 1 / 2 \mathrm{ka} 0.253 \pm 0.023 \mathrm{~h}$. and $\mathrm{t} 1 / 2 \alpha$ $0.253 \pm 0.023 \mathrm{~h}$.). In addition, the MRT was significantly prolonged $(3.93 \pm 0.47 \mathrm{hrs}$.) for the TC-NE formula than for TC- Powder $(2.77 \pm 0.29 \mathrm{hrs}$.). The prolonged t $1 / 2 \mathrm{ka}$, $\mathrm{t} 1 / 2 \alpha$ and tmax for the TC-NE formula indicated the persistence of Tetracycline for prolonged time with higher AUC, which is reflected by the higher bioavailability of TC-NE $(29.2 \pm 2.3 \%)$ than that for TC-powder (13.9 \pm $0.8 \%)$ after oral administration.

The pharmacokinetics variables that describe the two compartment disposition of tetracycline following a single oral and IV administration of TC-Powder and TC-NE formulas presented in (Table 2).

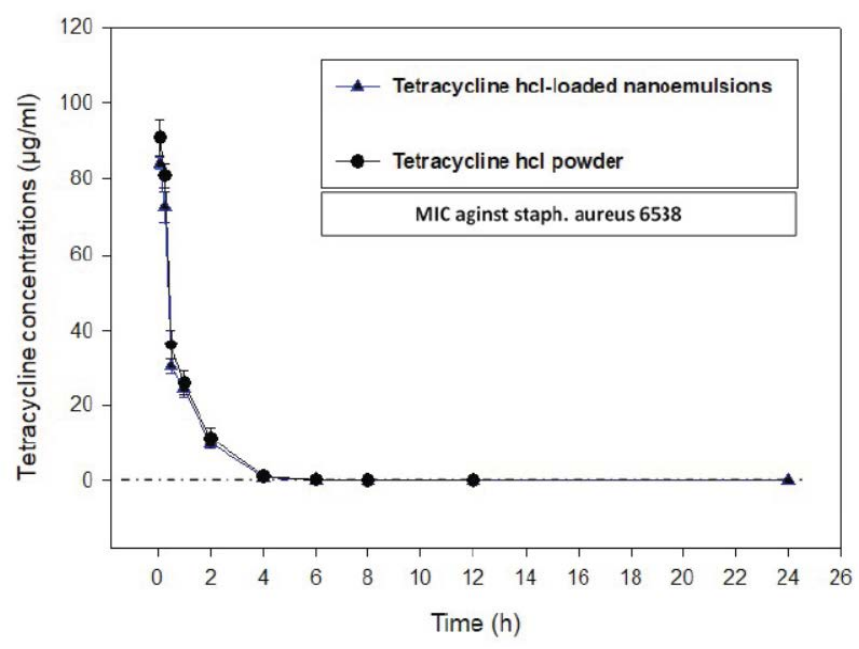

Figure 3: The time concentration relationship of Tetracycline hydrochloride (TC-Powder) or Tetracycline loaded nanoemulsion (TC-NE) after IV administration $(50 \mathrm{mg} / \mathrm{kg}$ b.wt) in white new zealand rabbits. (Mean \pm $\mathrm{SD}, \mathrm{N}=8)$.

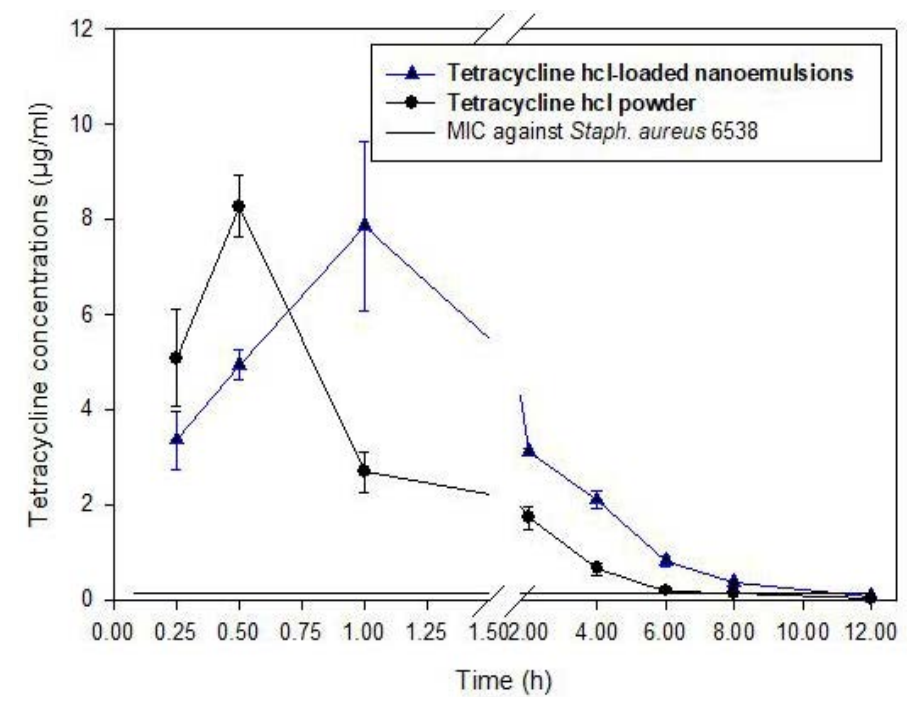

Figure 4: The time concentration relationship of Tetracycline hydrochloride (TC-Powder) or Tetracycline loaded nanoemulsion (TC-NE) after oral administration $(50 \mathrm{mg} / \mathrm{kg}$ b.wt) in white new zealand rabbits. (Mean \pm $\mathrm{SD}, \mathrm{N}=8)$.

\section{DISCUSSION}

Six systems composed of one of the two oils; IPM (ester of a long-chain fatty acid) or MIG (triglycerides of medium-chain fatty acids), surfactants; Cremophor RH40 (non-ionic surfactant, HLB=14-16) and cosurfactant; PEG 400 by the water titration method, Oil/water $(\mathrm{o} / \mathrm{w})$ (Kommuru et al., 2001). PEG 400 as being a cosurfactant; reduced the critical packing values (CPP). Oil/water $(\mathrm{o} / \mathrm{w})$ nanoemulsions ready owing to the high HLB value of the surfactant of the surfactants (Shinoda et al., 1991). 
Table 1: Mean droplet size (MDS), zeta potential (ZP) measurements and polydispersity index (PDI) of selected formulae.

\begin{tabular}{|c|c|c|c|c|c|c|}
\hline \multirow[t]{2}{*}{ Formula } & \multicolumn{3}{|c|}{ Composition } & \multirow{2}{*}{$\begin{array}{l}\text { Mean droplet } \\
\text { size (MDS) nm }\end{array}$} & \multirow{2}{*}{$\begin{array}{l}\text { Zeta potential } \\
\text { (ZP) } \mathrm{mV}\end{array}$} & \multirow{2}{*}{$\begin{array}{l}\text { Polydispersity } \\
\text { index (PDI) }\end{array}$} \\
\hline & Miglyol & $\begin{array}{l}\text { Cremophor RH40/ } \\
\text { PEG400 (1:1) }\end{array}$ & Water & & & \\
\hline F1 & 10 & 50 & 40 & $32.33 \pm 3.81$ & $-33.47 \pm 2.11$ & $0.11 \pm 0.01$ \\
\hline $\mathrm{F} 2$ & 15 & 50 & 35 & $52.79 \pm 4.38$ & $-28.90 \pm 4.22$ & $0.21 \pm 0.00$ \\
\hline F3 & 20 & 50 & 30 & $101.5 \pm 9.86$ & $-25.45 \pm 3.43$ & $0.41 \pm 0.07$ \\
\hline Drug-free Nanoemulsion (NE) & 10 & 50 & 40 & $25.52 \pm 3.37$ & $-31.56 \pm 3.92$ & $0.10 \pm 0.00$ \\
\hline
\end{tabular}

Table 2: Tetracycline pharmacokinetic parameters in plasma after oral and IV administration of tetracycline $\mathrm{HCl}$ powder (TC-Powder) and tetracycline Hcl loaded nanoemulsion (TC-NE) $(50 \mathrm{mg} / \mathrm{kg}$ b.wt) in male white new zealand rabbits. Tetracycline concentration was assessed using High Performance Liquid Chromatography (Mean \pm SD, $n=8$ ). $P$ value $<0.05$ was considered significant $(*)$ while, $\mathrm{P}$ value $<0.005$ was considered highly significant $\left.{ }^{* *}\right)$.

\begin{tabular}{|c|c|c|c|c|c|}
\hline \multirow[t]{2}{*}{ Parameter } & \multirow[t]{2}{*}{ Unit } & \multicolumn{2}{|l|}{ Oral administration } & \multicolumn{2}{|l|}{ IV administration } \\
\hline & & $\begin{array}{l}\text { Tetracycline } \mathrm{HCl} \text { powder } \\
\text { (TC-Powder) }\end{array}$ & $\begin{array}{l}\text { Tetracycline loaded } \\
\text { nanoemulsion } \\
\text { (TC-NE) }\end{array}$ & $\begin{array}{l}\text { Tetracycline } \mathrm{HCl} \\
\text { powder } \\
\text { (TC-Powder) }\end{array}$ & $\begin{array}{l}\text { Tetracycline loaded } \\
\text { nanoemulsion } \\
\text { (TC-NE) }\end{array}$ \\
\hline $\mathrm{k} 10$ & $1 / \mathrm{h}$ & $1.49 \pm 0.11$ & $0.700 \pm 0.102^{* *}$ & & \\
\hline k12 & $1 / \mathrm{h}$ & $0.969 \pm 0.208$ & $0.379 \pm 0.104^{* *}$ & $0.608 \pm 0.241$ & $0.795 \pm 0.165$ \\
\hline $\mathrm{k} 21$ & $1 / \mathrm{h}$ & $0.391 \pm 0.135$ & $0.406 \pm 0.335$ & $1.09 \pm 0.29$ & $1.26 \pm 0.16$ \\
\hline$t_{1 / 2 \alpha}$ & $\mathrm{h}$ & $0.265 \pm 0.025$ & $0.550 \pm 0.090^{* *}$ & $0.289 \pm 0.0446$ & $0.247 \pm 0.0289$ \\
\hline$t_{1 / 2 \beta}$ & $\mathrm{h}$ & $3.33 \pm 0.68$ & $4.22 \pm 1.66$ & $1.20 \pm 0.26$ & $1.12 \pm 0.09$ \\
\hline $\mathrm{t}_{1 / 2 \mathrm{ka}}$ & $\mathrm{h}$ & $0.253 \pm 0.023$ & $0.518 \pm 0.091^{* *}$ & & \\
\hline CL & L.h $/ \mathrm{kg}$ & $4.350 \pm 0.2522$ & $0.800 \pm 0.1398^{* *}$ & $0.602 \pm 0.0304$ & $0.67 \pm 0.026$ \\
\hline $\mathrm{T}_{\max }$ & $\mathrm{h}$ & $0.397 \pm 0.033$ & $0.869 \pm 0.059^{* *}$ & & \\
\hline $\mathrm{C}_{\max }$ & $\mu \mathrm{g} / \mathrm{ml}$ & $6.78 \pm 0.66$ & $6.38 \pm 0.91$ & & \\
\hline $\mathrm{AUC}_{0 \text {-inf }}$ & $\mu \mathrm{g} / \mathrm{ml} . \mathrm{h}$ & $11.5 \pm 0.6$ & $21.8 \pm 2.08^{* *}$ & $74.8 \pm 2.9$ & $83.3 \pm 4.2^{* *}$ \\
\hline AUMC & $\mu \mathrm{g} / \mathrm{ml} . \mathrm{h}^{2}$ & $32.0 \pm 4.4$ & $86.3 \pm 17.4^{* *}$ & $99.3 \pm 20.2$ & $87.1 \pm 4.2$ \\
\hline MRT & $\mathrm{h}$ & $2.77 \pm 0.29$ & $3.93 \pm 0.47^{* *}$ & $1.19 \pm 0.20$ & $1.17 \pm 0.06$ \\
\hline $\mathrm{T}>\mathrm{MIC}$ & $\mathrm{h}$ & $7.1 \pm 0.32$ & $10.36 \pm 0.64^{* *}$ & & \\
\hline $\mathrm{F}$ & $\%$ & $13.9 \pm 0.8$ & $29.2 \pm 2.3^{* *}$ & & \\
\hline $\mathrm{C} 0$ & $\mu \mathrm{g} / \mathrm{ml}$ & & & $111.7 \pm 8.5$ & $104.8 \pm 2.7^{*}$ \\
\hline $\mathrm{Vd}_{\mathrm{ss}}$ & $\mathrm{L} / \mathrm{kg}$ & & & $0.71 \pm 0.10$ & $0.78 \pm 0.06^{*}$ \\
\hline
\end{tabular}

K10: rate constant for absorption; k12: rate constant for compartment 1 to 2; k21: rate constant for compartment 2 to $1 ; \mathrm{t}_{1 / 2 \alpha}$ : apparent distribution half-life $; \mathrm{T}_{1 / 2 \beta}$ : the apparent elimination half-life; $\mathrm{t}_{1 / 2 \mathrm{ka}}$ : absorption half -life; $\mathrm{t}_{\max }$ : time of occurrence of $\mathrm{C}_{\max } ; \mathrm{C}_{\max }$ : maximal plasma concentration; $\mathrm{AUC}_{0}$ : area under the plasma concentration-time curve from time 0 to last sample time; $\mathrm{AUC}_{0 \text {-inf }}$ : area under the plasma concentration-time curve from time 0 to infinity; AUMC: area under the moment curve; MRT: mean residence time from time 0 to infinity; F: bioavailability; C0: plasma concentration at time $0 ; \mathrm{Vd}_{\mathrm{ss}}$ volume of distribution at steady state.

There was direct relation between the $\mathrm{S} / \mathrm{CoS}$ ratio and the clear zones showed in phase diagrams. The largest clear zones accomplished with Mig-based systems prepared using $\mathrm{S} / \mathrm{CoS}$ mixture ratios of $1: 1$. This could be explained in light of better micelles formation in presence of higher $\mathrm{S} /$ $\mathrm{CoS}$ mixture ratios, which consequences in enhancing the solubilization capacity of the nanoemulsion (Kawakami et al., 2002). Widest clear zone were achieved with Migbased system, Cremophor RH40/PEG 400 in ratio 1:1. To ensure the safety of the ready formulae, the least amount (50\%) of S/CoS mixture was chosen (Khalil et al., 2015).
Three formulae (F1, F2, and F3) were taken containing Mig at concentrations of 10,15 and 20\%. As mentioned by (Lawrence and Rees, 2000) nanoemulsion for IV administration, diluted with water without causing precipitation of the drug during use in clinic.

The observed signs of creaming and phase separation with F3 in the second stage of thermodynamic stability studies could be attributed to its high oil content where the surfactants failed to emulsin this amount of oil under further stress caused by the centrifugation process. 
Reported turbidity upon freezing at $-21{ }^{\circ} \mathrm{C}$, which disappeared on thawing is in line with those reported by Ammar et al. (2009) that attributed to coagulation of the internal phase at such low temperature. The small size of nanoemulsions could be justified by the cosurfactant molecules into the surfactants film that lowers the fluidity and surface viscosity of the interfacing film and decreases the radius of curvature of the droplets. Those forming transparent systems (Tenjarla, 1999). Regarding the size of the selected formulae, it was obvious that adding a higher amount of oil resulted in increasing the MDS. This is due to oil droplet of the nanoemulsion by increasing the oil amount (Yuan et al., 2006). Regarding PDI, the 0 value specify monodispersed particle population, while a value of 1 suggests highly polydispersed vesicles (Zeisig et al., 1996). The narrow PDI values of all TC-NE revealed narrow size distributions and good homogeneity.

A system considered stable when $\mathrm{ZP}$ possesses a value about $\pm 30 \mathrm{mV}$; where the value ensures the electric repulsion between particles (Du et al., 2009). The formulated TC$\mathrm{NE} Z \mathrm{ZP}$ values ranged from -25.45 to $-33.47 \mathrm{mV}$ (Table 1) indicating that they have enough charges that would inhibit their aggregation (Silva et al., 2015; FDA, 2014).

The pharmacokinetics of tetracycline hydrochloride released from TC- NE (sustained release formula) was studied after a single IV and oral administration $(50 \mathrm{mg} /$ $\mathrm{kg} \mathrm{b}$. wt.) and compared to that of TC- Powder. Following IV administration, detected tetracycline concentration in plasma at $0.083 \mathrm{~h}$ was $91.03 \pm 4.71$ and $84.20 \pm 1.60 \mu \mathrm{g} /$ $\mathrm{ml}$ and persisted exceeding MIC for at least 12 hours in all rabbits treated with TC-Powder and 24 hours for TC$\mathrm{NE}$, respectively. These results supported by the results in rabbits (Saber et al., 2019a) whom reported persistence of TC-NE in rabbits plasma than TC-powder. The prolonged persistence of tetracycline in rabbits plasma after IV and oral administration of TC-NE enhanced the time dependent activity of tetracycline. Consistently, Neuschl (1991) reported CTC serum levels averaged $2.3 \mathrm{mg} / 13 \mathrm{~h}$ after a single oral dose of $20 \mathrm{mg} / \mathrm{kg}$ b.wt. in californian rabbits and declined to a mean value of $0.09 \mathrm{mg} / 1$ by $12 \mathrm{~h}$, and to $0.08 \mathrm{mg} / \mathrm{l}$ by $24 \mathrm{~h}$. Peak plasma concentrations of $3.6 \mathrm{mg} / 1$ were observed in rat $2 \mathrm{~h}$ after treatment, declining to $0.5 \mathrm{mg} / 1$ after $6 \mathrm{~h}$. (Berté and Vandoni, 1962).

Following IV administration tetracycline had higher volume of distribution Vdss $(0.78 \pm 0.06 \mathrm{~L} / \mathrm{kg})$ in TC$\mathrm{NE}$ than in TC-Powder $(0.71 \pm 0.10 \mathrm{~L} / \mathrm{kg})$ and clearance rate, CL $(0.67 \pm 0.026 \mathrm{~L} . \mathrm{h} / \mathrm{kg})$ in TC-NE than in TCPowder $(0.602 \pm 0.0304 \mathrm{~L} . \mathrm{h} / \mathrm{kg})$. The former results showed enhancement of TC delivery by nanoemulsion system (Aboofazeli, 2010). Consistent results obtained by Saber et al. (2019a) and Percy and Black (1988) in male and female rabbits after IV administration $10 \mathrm{mg} / \mathrm{kg}$. In contrast to results reported by Nielsen and Gyrd-Hansen (1996) who measured disposition of TC in pigs received a dose of $10 \mathrm{mg} / \mathrm{kg}$ intravenously, TC was present in plasma up to 30 hours and volume of distribution was $1.2 \mathrm{~L} /$ $\mathrm{kg}$ body weight. The later variation may be attributed to species difference.

The higher volume of distribution and prolonged elimination supported by the significant higher AUC 0 -inf $(83.3 \pm 4.2 \mu \mathrm{g} / \mathrm{ml} . \mathrm{h}$ for TC-NE and $74.8 \pm 2.9 \mu \mathrm{g} / \mathrm{ml}$.h for TC-Powder. These results supported by the results obtained by Saber et al. (2019a) in rabbits; Percy and Black (1988) in male and female rabbits and disagree with Kniffen et al. (1989) and Agwuh and MacGowan (2006) in pigs.

After oral administration of TC-NE and TC-Powder (50 $\mathrm{mg} / \mathrm{kg} \mathrm{b} . \mathrm{wt}$ ) tetracycline detected at $0.25 \mathrm{~h}$. and the lowest detected concentration was at least for $8 \mathrm{~h}$ for TC-Powder and about 11 hours TC-NE. Our results supported by results in rabbits (Saber et al. (2019a)), in rats (Berte and Vandoni, 1962), in female rats and male guinea-pigs (Eisner et al., 1953). Tetracycline is time dependent, this suggested that sustained release is critical for its efficacy. Following oral admistiration TC-NE formula had prolonged $t>$ MIC of $10.36 \pm 0.64$ compared to $7.1 \pm 0.32 \mathrm{~h}$ in TC-powder which is suspected with delayed distribution half-life time $\mathrm{t}_{1 / 2 \alpha}$ of $0.550 \pm 0.090 \mathrm{~h}$ than that in TC- powder 0.253 $\pm 0.023 \mathrm{~h}$ as well as the significantly prolonged MRT $(3.93 \pm 0.47 \mathrm{hrs}$. $)$ for the TC-NE formula than for TCPowder $(2.77 \pm 0.29 \mathrm{hrs}$.). These results supported the time dependent activity of tetracycline, increased bioavailability and might be positively reflected on the clinical activity of TC-NE in treatment of tetracycline sensitive bacteria.

Following oral administration, tetracycline was rapidly absorbed after administration of TC-Powder and TC-NE with significant longer absorption half-life $\mathrm{t}_{1 / 2 \mathrm{ka}}$ for 0.518 $\pm 0.091 \mathrm{~h}$. in TC-NE and $\mathrm{t}_{1 / 2 \mathrm{ka}} 0.253 \pm 0.023 \mathrm{~h}$ for TCPowder. These results were in agreement with (Agwuh and MacGowan, 2006). Generally, after oral administration the reported significant short absorption half-life in TCPowder than TC-NE t1 $1_{/ 2 \otimes} 0.550 \pm 0.0902 \mathrm{~h}$ and $\mathrm{t}_{1 / 2 \otimes} 4.215 \pm$ $1.6613 \mathrm{~h}$ that indicated rapid absorption of the drug in both tested forms and routes were shorter than those reported in rabbits $(2.0 \mathrm{~h})$ (Percy and Black, 1988), chickens (2.8 h) (Anadon et al. 1985) and pigs (2.8 h) (Kniffen et al., 1989). Consequently, significant higher bioavailability reported for TC-NE $29.182 \pm 2.2784 \%$ than TC-Powder $13.858 \pm$ $0.7505 \%$ in treated rabbits.

The significant higher $\mathrm{AUC}_{0 \text {-inf }}(21.837 \pm 2.0784 \mu \mathrm{g} / \mathrm{ml} . \mathrm{h})$ and prolonged MRT (3.926 $\pm 0.4712 \mathrm{~h}$.) for TC-NE than for TC-Powder; $\mathrm{AUC}_{0 \text {-inf }}(11.526 \pm 0.6415 \mu \mathrm{g} / \mathrm{ml} . \mathrm{h})$ and MRT $(2.771 \pm 0.2932 \mathrm{~h}$.), which reflected by the higher bioavailability of TC-NE $(29.2 \pm 2.3 \%)$ than that for 
TC-powder $(13.9 \pm 0.8 \%)$ after oral administration that supported the sustained release hypothesis and time dependent activity of tetracycline. These results were in accordance with; Tamilvanan (2004); Tamilvanan et al. (2005); Li et al. (2008) and Aboofazeli (2010). Nanocarriers improves the pharmacokinetics activity of the carried drug (Shafiq et al., 2007; Han et al., 2009; Kotta et al., 2013; Sharma et al., 2014; Yen et al., 2018). Moreover, the recorded time above MIC of $0.14 \mu \mathrm{g} / \mathrm{ml}$ against Staphylococcus aureus 6538 (Saber et al., 2019a), were Longer in TC-NE than TC-Powder group following both oral and IV administration.

\section{CONCLUSIONS}

The formulated Tetracycline loaded nanoemulsion formulation had improved oral bioavailability and prolonged the blood concentration time than TC-Powder. Further clinical studies are required to prove dosage that supports clinical efficiency.

\section{ACKNOWLEDGMENTS}

TC-NE was prepared in Dept. of Pharmaceutical, faculty of Pharmacy, Cairo University. The experimental work of the research was facilitated and completed in department of pharmacology faculty of veterinary medicine, Cairo University.

\section{ETHICAL APPROVAL}

The research plan was approved from Cairo University institutional animal care and use committee (CU-IACUC) with approval number CU-II-F-99-18.

\section{CONFLICT OF INTEREST STATEMENT}

The authors have no conflict of interests to declare regarding the publication of this paper. Also, the authors declare that the work was self-funded.

\section{AUTHOR CONTRIBUTION}

AMA, SAE and MMA designed and planned this study. WHA prepared and characterized TC-NE. SAE, MMA, MSS and OAF performed experimental work, samples collection and all laboratory tests. All authors shared manuscript writing, drafted, revised the manuscript and approved the final manuscript.

\section{REFERENCES}

-Abdel Aziz EA, Khairy MH, El-Nabtity SM, Hamed EE, Saffaf BA (2017). Pharmacodynamic and Pharmacokinetic Studies on Tetracycline Hydrochloride in Rabbits. Zagazig Vet. J., 45(3): 218-227. https://doi.org/10.21608/zvjz.2017.7945
-Aboofazeli R (2010). Nanometric scaled emulsions (Nanoemulsions). Iranian J. of Pharmac. Res., 9: 325-326.

-Agwuh KN, MacGowan A (2006). Pharmacokinetics and pharmacodynamics of the tetracyclines including glycylcyclines. J. Antimicrobial Chemoth. 58: 256-265. https://doi.org/10.1093/jac/dkl224

-Ahmad J, Kohli K, Mir SR, Amin S (2011). Formulation of SelfNanoemulsifying Drug Delivery System for Telmisartan with Improved Dissolution and Oral Bioavailability. J. Dispersion Sci. Technol., 32(7): 958-968. https://doi.org/1 0.1080/01932691.2010.488511

-Ahmad J, Kohli K, Mir SR, Amin S (2012). Selfemulsifying nanocarriers for improved oral bioavailability of lipophilic drugs. Rev. Adv. Sci. Eng., 1(2): 134-147. https://doi. org/10.1166/rase.2012.1009

- Ammar HO, Salama H, Ghorab M, Mahmoud A. (2009). Nanoemulsion as a potential ophthalmic delivery system for dorzolamide hydrochloride. J. Am. Ass. Pharmac. Scientists, 10: 808. https://doi.org/10.1208/s12249-009-9268-4

-Anadon A, Martinez-Larranaga MR, Diaz MJ (1985). Pharmacokinetics of tetracycline in chickens after intravenous administration. Poult. Sci., 64: 2273- 2279. https://doi.org/10.3382/ps.0642273

- Baby PM, Jacob SS, Kumar R, Kumar P (2017). An innovative approach for serial injection in marginal vein and blood collection from auricular artery in New Zealand white Rabbit. Methods X, 4: 457-460. https://doi.org/10.1016/j. mex.2017.11.001

- Berté F, Vandoni G (1962). On the intestinal absorption and organotropism of some tertacyclines. Chemotherapia, 5: 219-230. https://doi.org/10.1159/000219995

- Carpenter JW, Christopher JM (2018). Exotic Animal Formulary. $5^{\text {th }}$ Ed.: 409-444.

- Chang WB,Zhao YB, CiYX,Hu LY (1992). Spectrofluorimetric determination of tetracycline and anhydrotetracycline in serum and urine. Analyst, 117: 1377-1378. https://doi. org/10.1039/an9921701377

- Chime SA, Kenechukwu FC, Attama AA (2014). Nanoemulsions-advances in formulation, characterization and applications in drug delivery. Application of nanotechnology in drug delivery. Intech Open (2014). From the Edited Volume, Intech Open Application of Nanotechnology in Drug Delivery. Edited by Ali Demir Sezer. https://www. intechopen.com/books/application-of-nanotechnology-indrug-delivery/nanoemulsions-advances-in-formulationcharacterization-and-applications-in-drug-delivery. https:// doi.org/10.5772/58673

- Costanzo AD, Angelico, R (2019). Formulation Strategies for Enhancing the Bioavailability of Silymarin: The State of the Art. Molecules. Jun; 24(11): 2155. https://doi.org/10.3390/ molecules 24112155

-Du WL, Niu SS, Xu YL , Xu ZR, Fan CL (2009). Antibacterial activity of chitosan tripolyphosphate nanoparticles loaded with various metal ions. Carbohydrate Polymers, 75: 385389. https://doi.org/10.1016/j.carbpol.2008.07.039

-Echols MS, Pollock C (2013). Blood Collection in Rabbits. (LafeberVet Web site. April 6, 2013) http://www. lafebervet.com/blood-collection-in-rabbits/.

-Eisner HJ, Stirn FE, Dornbush AC, Oleson JJ (1953). The enhancement of serum levels of Aureomycin experimental animals. J. Pharmacol. Exp. Therap. 108: 442-449.

-El Badawy SA, Amer AM, Kamel GM, Eldeib KM. Constable PD (2015). Comparative pharmacokinetics 
using a microbiological assay and high performance liquid chromatography following intravenous administration of cefquinome in lactating goats with and without experimentally induced Staphylococcus aureus mastitis. Small Ruminant Res., 133: 67-76. https://doi.org/10.1016/j. smallrumres.2015.11.004

-El-Assal MI, El-Gendy MA, Tadros MI, El-Gazayerly ON (2018).Olmesartan medoxomil-loaded self-nanoemulsifying drug delivery systems: Design, in-vitrocharacterization and pharmacokinetic assessments in rabbits via LC - MS/MS. Int. J. Pharmac. Sci. Res., 9 (3): 945-955.

-FDA (2014). CFR-Code of Federal Regulations Title 21-Food and Drugs.

- Gupta S, Kesarla R, Omri A (2013). Formulation Strategies to Improve the Bioavailability of Poorly Absorbed Drugs with Special Emphasis on Self-Emulsifying Systems. ISRN Pharm. 848043. https://doi.org/10.1155/2013/848043

-Han M, He CX, Fang QL, Yang XC, Diao YY, Xu DH, He QH, Hu YZ, Liang WQ, Yang B, Gao JQ (2009). A novel camptothecin derivative incorporated in nano-carrier induced distinguished improvement in solubility, stability and anti-tumor activity both in vitro and in vivo. Pharmac. Res., 26: 926-935. https://doi.org/10.1007/s11095-0089795-9

- Kawakami K, Yoshikawa T, Moroto Y, Kanaoka E, Takahashi K, Nishihara Y, Masuda K (2002). Microemulsion formulation for enhanced absorption of poorly soluble drugs: I. Prescription design.J. Controlled Release, 81: 65-74. https:// doi.org/10.1016/S0168-3659(02)00049-4

- Khalil RM, Basha M, Kamel R (2015). Nanoemulsions as parenteral drug delivery systems for a new anticancer benzimidazole derivative: formulation and in-vitro evaluation. Egypt J. Pharmac. Sci., 14: 166-173. https://doi. org/10.4103/1687-4315.172862

- Kniffen TS, Bane DP, Hall WF, Koritz GD, Bevill RF (1989). Bioavailability, pharmacokinetics, and plasma concentration of tetracycline hydrochloride fed to swine. Am. J. Vet. Res., 50: 518-521.

- Kommuru T, Gurley B, Khan M, Reddy I (2001). Selfemulsifying drug delivery systems (SEDDS) of coenzyme Q10: formulation development and bioavailability assessment. Int. J Pharm., 212: 233-246. https://doi. org/10.1016/S0378-5173(00)00614-1

- Kotta S, Khan A. W, Ansari S. H, Sharma RK and Ali J. (2013). Formulation of nanoemulsion: a comparison between phase inversion composition method and highpressure homogenization method. Drug Delivary, 22: 455466. https://doi.org/10.3109/10717544.2013.866992

-Lawrence MJ, Rees GD (2000). Microemulsion-based media as novel drug delivery systems. Adv. Drug Delivery Rev., 45: 89-121. https://doi.org/10.1016/S0169-409X(00)00103-4

-Li J, Nie S, Yang X, Wang C, Cui S, Shenyang WP (2008). Optimization of tocol emulsions for the intravenous delivery of clarithromycin. Int. J. Pharm., 356: 282-290. https://doi. org/10.1016/j.ijpharm.2007.12.046

-McCormick J, Fox SM, Smith LL, Bitler BA, Reichenthal J, Origoni VE, Muller WH, Winterbottom R, Doerschuk AP (1957). Studies of the reversible epimerization occurring in the tetracycline family. The preparation, properties and proof of structure of some 4-epi-tetracyclines. J. Amir. Chem. Soc., 79: 2849-2858. https://doi.org/10.1021/ ja01568a050

-Mestorino N, Errecalde JO (2012). Pharmacokinetic-
Pharmacodynamic Considerations for Bovine Mastitis Treatment, A Bird's-Eye View of Veterinary Medicine, Dr. Carlos C.Perez-Marin(Ed.).https://doi.org/10.5772/31721

- Neuschl J (1991). Comparison of some pharmacokinetic parameters of tetracyclines which are most frequently used in veterinary medicine. Arch. Exp. Vet., 45: 105-112.

-Nielsen P, Gyrd-Hansen N (1996). Bioavailability of oxytetracycline, tetracycline and chlortetracycline after oral administration to fed and fasted pigs. J. Vet. Pharmacol. Therap., 19 (4): 305-311. https://doi. org/10.1111/j.1365-2885.1996.tb00054.x

- Oka H (1995). Chemical Analysis of Tetracycline Antibiotics. In: H Oka, H Nakazawa, KI Harada, JD Macneil (Eds). Chem. Anal. Antibiot. Used Agric., AOAC Int. Darlington, VA 22201-3301, USA.

-Papich MG (2016). in Saunders Handbook of Veterinary Drugs - Elsevier eBook on VitalSource, $4^{\text {th }} \mathrm{Ed}$.

- Parasuraman S, Raveendran R, Kesavan R (2010). Blood sample collection in small laboratory animals. J. Vet. Pharmacol. Therap., 1(2): 87-93. https://doi.org/10.4103/0976500X.72350

- Percy DH, Black WD (1988). Pharmacokinetics of tetracycline in the domestic rabbit following intravenous or oral administration. Canad. J. Vet. Res., 52: 5-11.

- Riviere JE, Spoo JW (2001). Tetracycline antibiotics. In: Adams, RH (Ed.), Veterinary pharmacology and therapeutics. $\left(8^{\text {th }}\right.$ Ed.), Ames, Iowa, USA, Iowa State Univ. Press, 828- 840.

- Saber MS, Amer AM, ElBadawy SA, Amer MM (2019 a). Pharmacological Studies on Tetracycline and Tetracycline Nanoemulsion Formulas. Egypt. J. Vet. Sce., 50(1): 1-11.

- Saber MS, Amer AM, ElBadawy SA, Amer MM, Othman AM, Ahmed-Farid OA (2019b). Comparative Pharmacodynamic And Histopathological Studies On Tetracycline Loaded Nanoemulsion And Tetracycline In Rabbits. Res. J. Pharm. Biol. Chem. Sci.,10 (1): 855-868.

-Saunders, RA, Davies RR (2005). Infectious diseases, in Notes on Rabbit Internal Medicine. Blackwell Publishing Ltd, 9600 Garsington Rd, Oxford, OX4 2DQ, UK. 175-198.

- Shafiq S, Shakeel F, Talegaonkar S, Ahmad FJ, Khar RK, Ali M (2007). Development and bioavailability assessment of ramipril nanoemulsion formulation. Eur. J. Pharm. Biopharm., 66 (2): 227-243. https://doi.org/10.1016/j. ejpb.2006.10.014

- Shalaby AR, Salama NA, Abou-Raya SA, Emam WH, Mehaya FM (2011). Validation of HPLC method for determination of tetracycline residues in chicken meat and liver. Food Chem., 124 (4): 1660-1666. https://doi.org/10.1016/j. foodchem.2010.07.048

-Sharma S, Sahni JK, Ali J, Baboota S (2014). Effect of highpressure homogenization on formulation of TPGS loaded nanoemulsion of rutin-pharmacodynamic and antioxidant studies. Drug Delivary, 22: 541-551. https://doi.org/10.31 09/10717544.2014.893382

- Shinoda K, Araki M, Sadaghiani A, Khan A, Lindman B (1991). Lecithin-based microemulsions: phase behavior and microstructure. J. Phys. Chem., 95: 989-993. https://doi. org/10.1021/j100155a091

- Silva HD, Cerqueira MA, Vicente AA (2015). Influence of surfactant and processing conditions in the stability of oil-in-water nanoemulsions. J. Food Eng., 167 ( Part B): 89-98. https://doi.org/10.1016/j.jfoodeng.2015.07.037

-Tamilvanan S (2004). Oil-in-water lipid nanoemulsions: Implications for parenteral and ocular delivering systems. 
Prog. Lipid Res., 43:489-533. https://doi.org/10.1016/j. plipres.2004.09.001

-Tamilvanan S, Schmidt S, Muller RH, Benita S (2005). In vitro absorption of plasma proteins onto the surface (charges) modified-submicron emulsions for intravenous administration. Euro. J. Pharm. Biopharm., 59: 1- 7. https:// doi.org/10.1016/j.ejpb.2004.07.001

- Tenjarla S (1999). Microemulsions: an overview and pharmaceutical applications. Crit. Rev. Ther. Drug Carrier Syst., 16 (5): 461-521. https://doi.org/10.1615/ CritRevTherDrugCarrierSyst.v16.i5.20

-Toutain PL, Bousquet-Melou A (2004). Bioavailability and its assessment. J. Vet. Pharm. Ther., 27: 455- 466. https://doi. org/10.1111/j.1365-2885.2004.00604.x

-Yen CC, Chen YC, Wu MT, Wang CC, Wu YT (2018). Nanoemulsion as a strategy for improving the oral bioavailability and anti-inflammatory activity of andrographolide. Int. J. Nanomed., 13: 669-680. https://doi. org/10.2147/IJN.S154824

-Yuan Y, Li SM, Mo FK, Zhong DF (2006). Investigation of microemulsion system for transdermal delivery of meloxicam. Int. J. Pharm., 321: 117-123. https://doi.org/10.1016/j. ijpharm.2006.06.021

-Zeisig R, Shimada K, Hirota S, Arndt D (1996). Effect of sterical stabilization on macrophage uptake in vitro and on thickness of the fixed aqueous layer of liposomes made from alkylphosphocholines. Biochim. Biophy. Acta (BBA)Biomembr. 1285: 237-245. https://doi.org/10.1016/S00052736(96)00167-8

-Zhang Y, Meirong, Zhoua J, Xie S (2010). PKSolver: An addin program for pharmacokinetic and pharmacodynamic data analysis in Microsoft Excel. Comput. Methods Programs Biomed., 99(3): 306-314. https://doi.org/10.1016/j. cmpb.2010.01.007 